\title{
Internalisasi nilai-nilai Pancasila dalam upaya mencegah radikalisme
}

\author{
Gernaida Krisna Pakpahan ${ }^{1 *}$, Ibnu Salman², Andreas Budi Setyobekti ${ }^{3}$, \\ Ivonne Sandra Sumual ${ }^{4}$, Apin Militia Christi ${ }^{5}$ \\ 1,3,4,5 Sekolah Tinggi Teologi Bethel Indonesia, Jakarta \\ ${ }^{2}$ Litbang Kementerian Agama Republik Indonesia, Jakarta \\ *Correspondence: gernaidapakpahan@sttbi.ac.id
}

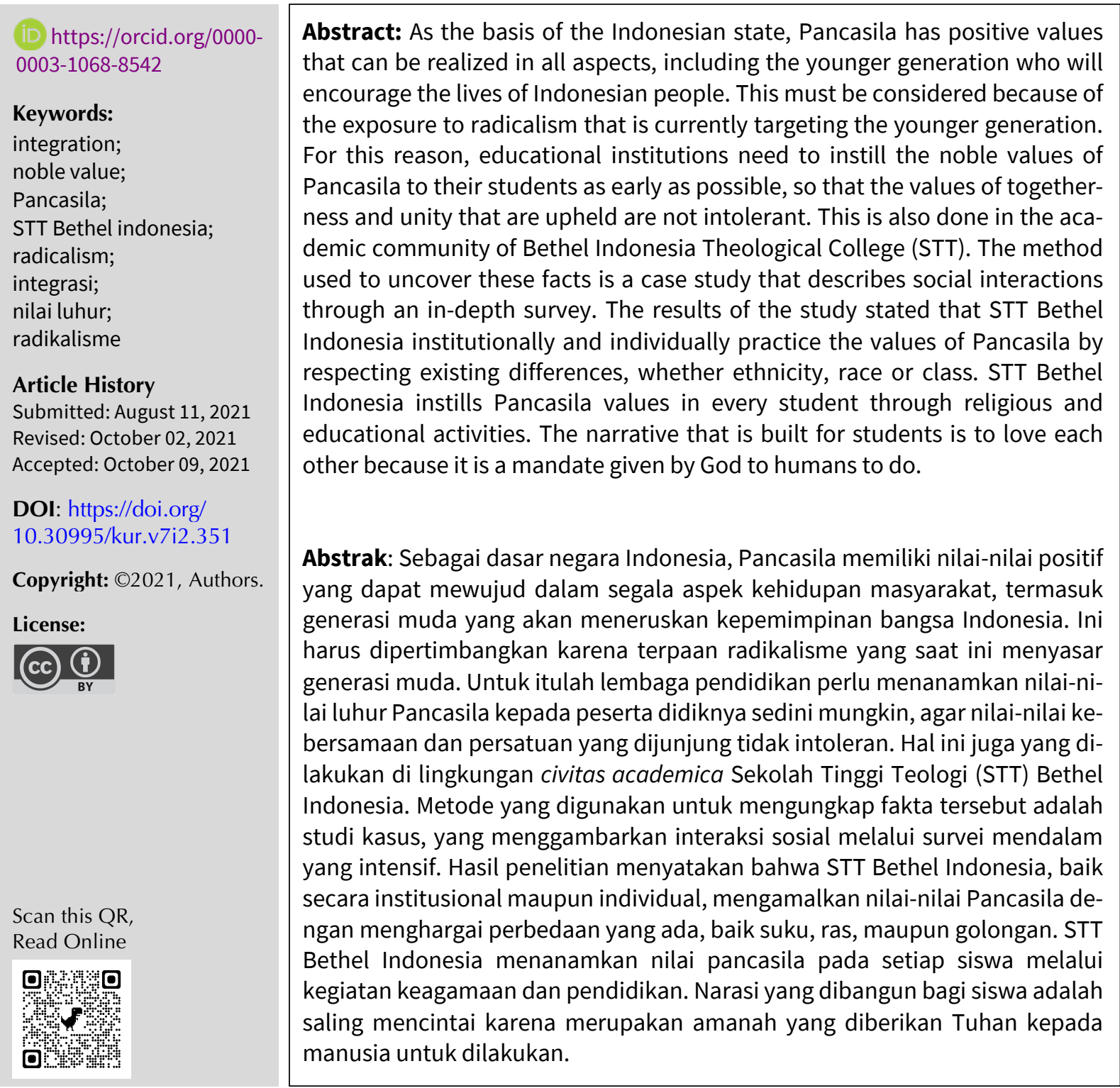

\section{Pendahuluan}

Tantangan generasi milenial di era digitalisasi ini adalah keberadaan mereka yang melek teknologi. Secara tidak langsung, hal ini membentuk pribadi generasi milenial yang bersifat digital 
native, orang-orang yang begitu menyukai segala hal yang visual. ${ }^{1}$ Internalisasi nilai-nilai Pancasila perlu digaungkan kembali, khususnya di kalangan mahasiswa sebagai penerus kepemimpinan bangsa. Beberapa peristiwa yang dihadapkan pada tereduksinya nilai Pancasila, yang disebabkan oleh pengaruh digitalisasi yang masuk dalam segala lini kehidupan; selain itu, pengaruh upaya memecah belah bangsa melalui kegiatan intoleransi dan radikalisme yang ramai diberitakan oleh media. Generasi milenial memiliki kemampuan yang cepat menyerap berbagai informasi yang dapat membentuk pola pikir dan cara hidup di tengah masyarakat Indonesia yang majemuk.

Indonesia kembali dikejutkan dengan peristiwa bom bunuh diri yang terjadi pada tanggal 28 Maret 2021, di pintu gerbang gereja Katedral Makassar. Berbagai media massa online memberitakan bahwa hal tersebut identik dengan sikap terorisme, yang dilakukan oleh pasangan suami-istri (L dan YSF). ${ }^{2}$ Kasus tersebut tidak hanya merugikan pemeluk agama tertentu yang diidentikkan dengan pelaku bom bunuh diri tersebut (Agama Islam), melainkan juga bagi pemeluk agama lain yang ada di Indonesia.

Peristiwa bom bunuh diri di atas, bisa saja dikategorikan sebagai akibat munculnya fundamentalisme agama yang berujung pada tindakan kekerasan dan teror yang bersembunyi di balik praktik keagamaan. Hal ini menunjukkan bahwa nilai-nilai Pancasila belum membumi dalam kehidupan masyarakat Indonesia. Semboyan Bhineka Tunggal Ika, hendaknya dihidupi di tengah kehidupan masyarakat yang multikultural seperti Indonesia. Beragam suku, budaya dan agama tumbuh berdampingan, sehingga perlu dikembangkan sikap yang pancasilais agar dapat menghindarkan masyarakat dari ekstrimisme yang mampu menumbuhkan sikap radikal.

Fakta yang ditemukan oleh Basri dan Dwinigrum dalam penelitiannya menunjukkan bahwa generasi milenial, terutama mahasiswa, merupakan generasi yang mudah disusupi oleh paham radikalisme. ${ }^{3}$ Hidayat dan Lubis menyatakan, pemberitaan media online mengenai radikalisme dapat mempengaruhi pola pemikiran pelajar yang kesehariannya hidup dengan teknologi. ${ }^{4}$ Subagyo dalam penelitiannya mengungkapkan sikap radikalisme bertumbuh subur dan cepat di kalangan generasi muda yang masih menempuh Pendidikan baik di sekolah, maupun perguruan tinggi. ${ }^{5}$ Pemerintah perlu mengambil tindakan untuk mencegah pertumbuhan paham radikalisme di generasi milenial.

Uraian di atas, mengindikasikan pudarnya nilai-nilai luhur yang melekat pada bangsa Indonesia, khususnya bagi mahasiswa seperti religiusitas, kejujuran, kesantunan, kebersamaan, dan lain sebagainya yang cukup menjadikan keprihatinan kita bersama. Mengintegrasikan nilai Pancasila di tengah masyarakat Indonesia bisa dimulai dari lembaga pendidikan, keluarga, dan masyarakat. Salah satu upaya yang sedang digalakkan oleh pemerintah adalah dengan membangun sumber daya manusia Indonesia dengan konsep pelajar Pancasila. ${ }^{6}$ Lembaga Pendidikan sebagai salah satu agent of change mengambil peran penting dalam membantu pemerintah mengintegrasikan nilai-nilai Pancasila di kalagan pelajar dan mahasiswa. Wujud konkret yang bisa dilakukan oleh lembaga pendidkan yakni dengan mempertajam sikap pancasilais melalui

\footnotetext{
${ }^{1}$ Doddy Doddy, "Internalisasi Nilai-Nilai Pancasila Perlu Diperkuat," Direktorat Jenderal Pendidikan Tinggi Kementerian Pendidikan, Kebudayaan, Riset Dan Teknologi.

${ }^{2}$ Wisnu Nugroho, "Bom Bunuh Diri Di Gerbang Katedral Makassar Dan Ancaman Teror Serentak," Kompas News (Jakarta, 2021), https://www.kompas.com/tren/read/2021/03/30/090623665/bom-bunuh-diri-di-gerbangkatedral-makassar-dan-ancaman-teror-serentak?page=all.

${ }^{3}$ Basri Basri and Nawang Retno Dwiningrum, "Potensi Radikalisme Di Perguruan Tinggi ( Studi Kasus Di Politeknik Negeri Balikpapan )," Jurnal Sosial Humaniora dan Pendidikan 3, no. 1 (2019): 84-91.

${ }^{4}$ Fadhil Pahlevi Hidayat and Faizal Hamzah Lubis, "Literasi Media Dalam Menangkal Radikalisme Pada Siswa" 5, no. 1 (2021): 31-41.

${ }^{5}$ Agus Subagyo, "Implementasi Pancasila Dalam Menangkal Intoleransi, Radikalisme Dan Terorisme," Jurnal Rontal Keilmuan Pancasila dan Kewarganegaraan 6 (1) (2020).

${ }^{6}$ Kementerian Pendidikan dan Kebudayaan, "Visi Misi Kementerian Pendidikan Dan Kebudayaan," Kementerian Pendidikan Dan Kebudayaan, last modified 2020, https://www.kemdikbud.go.id/main/tentangkemdikbud/visi-dan-misi.
} 
cara mengintegrasikan nilai-nilai tersebut dalam pembelajaran di kelas untuk mencegah terjadinya lost value dan lost morality pada generasi milenial.

Kehidupan kampus yang sangat heterogen, dan cenderung di dominasi oleh salah satu pemeluk agama tertentu bisa memicu terjadinya konflik internal. Hal ini terlihat nyata pada dinamika kehidupan salah satu sekolah tinggi teologi Kristen yang terletak di Petamburan, Jakarta Pusat, yang dikenal dengan nama Sekolah Tinggi Teologi (STT) Bethel Indonesia Jakarta. Lingkungan sekitar STT Bethel Indonesia sangat heterogen, dihuni dari berbagai suku, agama, dan bahkan berdekatan dengan salah satu ormas agama. Beberapa kali terjadi konflik di sekitar lingkungan STT, namun keamanan STT Bethel Indonesia tetap kondusif.7 Hasil pengamatan memperlihatkan, dalam beberapa konflik yang pernah terjadi, anak-anak muda yang paling banyak terlibat dalam peristiwa tersebut. Inilah yang menjadi kekuatiran, karena anak muda sangat mudah terprovokasi, apalagi menyangkut isu agama.

Di masa Pandemi Covid-19, sekitar bulan April 2020 ditemukan 34 mahasiswa yang berada di asrama Bethel terpapar positif Covid-19 dan dibawa ke Wisma Atlit.8 Kasus ini mengakibatkan akses ke kampus mesti di-lockdown, dan memberikan kecemasan kepada masyarakat sekitar kampus karena takut tertular oleh virus Covid-19. Peristiwa ini menciptakan kesenjangan di sekitar lingkungan Bethel, bahkan mahasiswa yang tinggal di kost sekitar kampus mesti keluar dari kost karena mereka tercatat sebagai mahasiswa STT Bethel Indonesia. Respon yang kurang baik dari masyarakat sekitar kampus merupakan akumulasi dari sikap ekstrim yang kemudian melahirkan intoleransi. Pihak STT Bethel Indonesia perlu membekali mahasiswa dengan pemahaman ideologi Pancasila yang benar agar tidak terjadi konflik keagamaan (respon balik) sesuai dengan visi misi pemerintah untuk menciptakan pelajar Pancasila.

Tujuan penelitian ini adalah untuk memperoleh data atau informasi akurat dan objektif tentang seberapa besar tingkat pengetahuan serta pemahaman Ideologi Pancasila di kalangan mahasiswa STT Bethel, dalam rangka meredam intoleransi dan radikalisme; serta, bagaimana integrasi nilai Pancasila di kalangan mahasiswa STT Bethel.

\section{Metode Penelitian}

Analisis di dalam artikel ini menggunakan metode penelitian studi kasus (case study). Pemilihan metode studi kasus dikarenakan hendak melakukan penafsiran yang tepat tentang karakteristikkarakteristik objek yang diteliti. Studi kasus, menurut Jacobs, biasa diterapkan dalam penelitian yang memotret skala kecil dalam kehidupan sosial yang nantinya dapat diterapkan secara umum atau menjadi contoh bagi komunitas sosial yang lain. ${ }^{9}$ Studi kasus lebih tampak (contrasted) pada survey intensif secara mendalam pada fenomena yang diteliti. Aktualitas integrasi nilai Pancasila dalam case studi ini menggunakan tiga pilihan kategori, yaitu: tinggi (high), sedang (moderate), dan rendah (low). Keputusan pada setiap kategori menunjukkan proses integrasi akan semakin baik jika berada pada kategori tinggi, begitupun sebaliknya.

\section{Pembahasan}

\section{Pancasila dan Lembaga Pendidikan Keagamaan}

Pancasila merupakan ideologi negara Republik Indonesia yang menjadi value, di mana kelima sila yang ada terintegrasi satu dengan lainnya. Pemaknaan pada setiap nilai-nilai yang dimiliki dalam setiap sila bersifat holistik dan netral (tidak berpihak pada golongan tertentu). Keunikan dari value Pancasila ini juga bisa digunakan oleh Lembaga keagamaan dalam hal ini Sekolah

\footnotetext{
${ }^{7}$ Ryan Hadi Suhendra, "Massa Berkumpul Dekat Markas FPI , Aparat TNI Dan," CNN Indonesia (Jakarta, November 2019), https://www.cnnindonesia.com/nasional/20191001021328-20-435512/massa-berkumpul-dekatmarkas-fpi-aparat-tni-dan-polri-siaga.

${ }^{8}$ Juli Hantoro, "Pasien Covid-19 Cluster Bethel Petamburan Dirujuk Ke Wisma Atlet," Metro Tempo (Jakarta, 2020), https://metro.tempo.co/read/1332388/pasien-covid-19-cluster-bethel-petamburan-dirujuk-ke-wismaatlet/full\&view=ok.

${ }^{9}$ H Schwartz and J Jacobs, Qualitative Sociology: A Method to The Madness (New York: Free Press, 1979).
} 
Tinggi Teologi yang menjadi pusat belajar bagi para mahasiswa. Pemahaman bahwa kelima sila ini saling terintegrasi dan terikat satu sama lain merupakan hal yang sangat penting. Pancasila ibarat sebagai manual book yang dapat merekatkan kesatuan dan persatuan masyarakat Indonesia yang sangat majemuk. Pelaksanaan Pancasila yang benar akan menciptakan keharmonisan dalam mencapai masyarakat Indonesia yang maju dan berkepribadian pancasilais. Kehidupan berbangsa dan bernegara didasari oleh nilai-nilai Pancasila.

Intisari dari sila pertama menujukkan bahwa negara Indonesia memercayai eksistensi ketuhanan yang bersifat esa. Manusia dipandang sebagai ciptaan Tuhan yang Maha Esa. Perwujudan dari sila pertama terlihat dalam tata aturan negara Republik Indonesia yang berakar pada spirit Ketuhaan yang maha Esa. Semua dijiwai oleh semangat ini yang menandakan Indonesia sebagai negara yang percaya akan eksistensi Tuhan dan bukan negara sekuler. ${ }^{10}$ Fakta ini, seharusnya mendorong terciptanya harmonisasi antar agama menjadi sesuatu yang real. Prinsip nilai dari sila pertama menjadi perekat kemajemukan kepercayaan yang ada di Indonesia. ${ }^{11}$

Interpretasi pada sila kedua menunjukkan bahwa negara Republik Indonesia sangat memrioritaskan mengenai harkat dan martabat manusia yang dipandang sebagai makhluk yang beradab. 12 Nilai ini menciptakan kesadaran masyarakat Indonesia untuk berperilaku yang berpadanan dengan norma-norma, budaya, dan hal-hal yang bersifat humanisme. Hal ini senada dengan ajaran Yesus Kristus mengenai: Siapakah sesamaku manusia. Interaksi yang dimaksudkan sila kedua, selain dengan manusia juga dengan alam semesta. Manusia juga perlu menjaga kelestarian alam yang dihuninya agar tercipta harmonisasi pada semua ciptaan Tuhan.

Makna dari sila ketiga mencerminkan keberadaan manusia yang monodualis. Realitas manusia yang monodualis sebagai makhluk individu sekaligus juga makhluk sosial. Secara individu, manusia memiliki keunikan yang merupakan ciri yang tidak dapat diseragamkan. Hal itu berkaitan dengan keragaman suku, golongan, ras, budaya dan agama. Secara sosial, manusia saling membutuhkan satu sama lain dan tidak dapat hidup sendiri-sendiri. Keragaman bukanlah alasan untuk tidak hidup dalam kesatuan, senada dengan semboyan Bhinneka Tunggal Ika. Ajaran Yesus Kristus menegaskan bahwa kesatuan yang tidak dibatasi tembok suku adalah semangat dari kekristenan. ${ }^{13}$ Salah satu contoh dalam Alkitab menjelaskan bagaimana tembok perbedaan suku dihancurkan oleh Yesus ketika bertemu dengan perempuan Samaria.

Penjelasan tentang nilai yang terkandung pada sila keempat, yaitu rakyat berperan utama untuk mendukung pokok Negara. ${ }^{14}$ Prinsip negara Republik Indonesia adalah dari; oleh; dan untuk rakyat. Sistem demokrasi yang dianut oleh negara Republik Indonesia terlihat jelas dalam sila ini, bahwa rakyat memiliki kedudukan yang sama baik dari segi hak dan kewajiban. Nilai demokrasi ditunjukkan melalui musyawarah untuk mencapai mufakat. Value yang terkandung pada sila kelima, yakni bahwa seluruh rakyat Indonesia mendapat perlakuan yang sama dari segi hukum, politik, sosial, ekonomi dan agama. Jadi tidak ada perbedaan perlakuan hanya karena status sosial; misal: pejabat negara, konglomerat dan sebagainya. Keadilan yang dimaksud, juga mengenai menikmati alam, mengusahakan alam dan hasil bumi yang ada di Indonesia.

\section{Pancasila dalam perspektif Teologi Bethel}

Gereja sebagai bagian integral warga negara Indonesia dipanggil untuk mencintai negara. Tanggung jawab gereja diwujudkan melalui kehadiran karyanya yang nyata di tengah-tengah

${ }^{10}$ Kaelan \& Zubaidi, 2007: 32-33

${ }^{11}$ Izak Lattu, "Performative Interreligious Engagement: Thinking About Sociology of Interreligious Relations [Performative Interreligious Engagement: Memikirkan Sosiologi Hubungan Lintas Agama]," in Sosiologi Agama Pilihan Berteologi Di Indonesia, 25 Tahun Pasca Sarjana Sosiologi Agama Universitas Kristen Satya Wacana (Salatiga: Fakultas Teologi UKSW, 2016).

${ }^{12}$ Kaelan and Zubaidi, Pendidikan Kewarganegaraan Untuk Perguruan Tinggi.

${ }^{13}$ Naftali Untung, "Kristus Dan Perempuan Samaria: Yohanes 4:1-42," in Misi Inklusif: Berjumpa Dengan Firman Dan Realitas Untuk Misi Yang Inklusif (Jakarta: STT Bethel Indonesia, 2017), 96.

${ }^{14}$ Kaelan and Zubaidi, Pendidikan Kewarganegaraan Untuk Perguruan Tinggi. 
masyarakat demi menjaga, memelihara dan membangun bangsanya. ${ }^{15}$ Indonesia dipahami sebagai anugerah Tuhan bagi setiap penduduknya, dengan segala heterogonitasnya, baik suku, budaya maupun bahasa, dan agama, termasuk di dalamnya gereja dan khususnya STT Bethel Indonesia. 16

Pancasila sebagai dasar negara, dengan semboyan Bhinneka Tungal Ika memungkinkan setiap warga bangsa terhimpun dan bersatu dalam keragaman budaya, suku, agama, ras dan latar bekakang lainnya. ${ }^{17}$ Karena itu, menjunjung tinggi nilai-nilai Pancasila yang terkandung di dalamnya memerlukan komitmen bersama dalam melestarikannya. Gereja Bethel dalam konteks mengimplementasikan Pancasila relevan dan bisa menjadi model dalam mengamalkan nilainilai Pancasila dilingkungan nya yang terdiri dari berbagai lembaga pendidikan (SD, SMP, SMA, dan STT Bethel), sehingga Pancasila bisa dipegang dan dipedomani secara khusus oleh seluruh warga Bethel, dan secara umum oleh segenap elemen bangsa, dalam menjalankan tugas dan kewajibannya. Heterogenitas dalam lembaga pendidikan Bethel bisa menjadi sendi-sendi kehidupan bersama yang diikat dalam implementasi sila demi sila, diejawantahkan dalam realitas hidup sehari-hari bersama warga bangsa lainnya. ${ }^{18}$

Teologi Kristen mendorong penerapan nilai-nilai Pancasila dalam hidup warga gereja tidaklah bertentangan, justru sebalinya, menjadi hal yang penting dan relevan dalam kedudukannya sebagai warga negara. Nilai-nilai yang terkandung dalam Pancasila itu dapat diwujudkan dalam rangka teologi praksis. Pokok penting dalam kepercayaan terhadap Tuhan Yang Maha Esa jelas terkait dengan Tuhan Sang Pencipta; la adalah pusat kehidupan sekaligus menjadi tujuan seluruh penyembahan. Dengan pemahaman bahwa seluruh tindakan dan karya manusia bagi kemuliaan Tuhan sendiri. Sebagai Pencipta, Allah memberi kuasa kepada manusia atas alam semesta untuk dikelola dan diusahakan. Bumi tempat manusia berdiam diberi untuk dieksplorasi dan dilestarikan demi keberlangsungan hidup manusia. Di sinilah providensia Allah dinyatakan, yang memungkinkan manusia mengembangkan seluruh kecakapan dan intelektualitasnya, agar berkarya maksimal dalam dunia ciptaan-Nya. ${ }^{19}$

Tujuan Allah menciptakan manusia untuk menjadikannya mitra dan kawan sekerja-Nya dalam mengelola alam ciptaanNya. Diciptakan dalam rupa dan gambarNya, baik laki-laki dan perempuan (Kej. 1:26-28). Selain mengelola alam, manusia diberi mandat untuk berkembang biak. Manusia diciptakan dalam keunikan sehingga mereka saling melengkapi satu dengan yang lain. Allah menciptakan manusia untuk hidup berdampingan dengan sesamanya, sehingga dalam pelaksanaan tugas dan panggilannya manusia dengan sesamanya mampu menyelesaikan tugas bersama itu. 20

Hidup setiap individu adalah anugerah Allah. Kesadaran manusia bahwa dirinya adalah citaan Allah yang istimewa menuntut tanggung jawab untuk taat terhadap perintah-Nya.21 Berbeda dengan mahluk ciptaan lain, manusia dipersiapkan Allah untuk menyembah, memuji dan melayani-Nya. Maka akan tampak bahwa orang yang mencitai Tuhan akan mampu menerima orang lain sebagi sesamanya dengan penuh kasih. Manusia dihadirkan untuk saling mengasihi dan mencintai. Dalam konteks implementasi nilai Pancasila sila pertama, manusia

\footnotetext{
${ }^{15}$ Paulus Sugeng Widjaja, "Aktualisasi Pancasila Berdasarkan Etika Kebajikan Kristiani," DUNAMIS: Jurnal Teologi dan Pendidikan Kristiani (2020).

${ }^{16}$ Andreas Budi Setyobekti, "Mengafirmasi Kembali Nilai-Nilai Pengajaran Gereja Bethel Indonesia," in Reaffirming Our Identity: Isu-Isu Terpilih Menjawab Perubahan Sekaligus Mempertahankan Identitas, ed. Junifrius Gultom and Frans Pantan (Jakarta: Bethel Press, 2014).

${ }^{17}$ Idjang Tjarsono, "Demokrasi Pancasila Dan Bhineka Tunggal Ika Solusi Integrasi," Transnasional (2013).

${ }^{18}$ Doni Septian, "PEMAHAMAN NILAI-NILAI PANCASILA DALAM MEMPERKUAT KERUKUNAN UMAT," TANJAK: Journal of Education and Teaching (2020).

${ }^{19}$ Joel Suh Tae Yun, "Reading the Fourfold Gospel From the Two Creation Stories in Genesis: A Creation Theological Understanding of the Fourfold Gospel for Holistic Mission," Transformation (2020). 2019.

${ }^{20}$ Andrew Steinmann, Genesis: An Introduction and Commentary, Tyndale Old Testament Commentaries,

${ }^{21}$ Wiryohadi Wiryohadi, "Gereja Berbasis Visi Dan Misi Kerajaan Allah," in Reaffirming Our Identity, ed. Junifrius Gultom and Frans Pantan, 1st ed. (Jakarta: STT Bethel Indonesia, 2014), 261.
} 
diarahkan pada upaya meyakini ke-Esa'an Tuhan sebagai bagian dari religiusitasnya manusia terhadap hasil ciptaan Tuhannya.

Gereja memiliki 5 panggilan yang harus dilakukan secara menyeluruh. Koinonia (persekutuan) merupakan salah satu tugas dan panggilan warga gereja, sekaligus sebagai upaya implementasi sila pertama: Ketuhanan yang maha Esa; koinonia dipanggil untuk bersekutu dengan Tuhan sekaligus pula bersekutu sesamanya. Manusia merupakan mahluk sosial, di mana setiap individu butuh persekutuan, baik dalam keluarga, gereja, masyarakat, dan bangsa. Demikian pentingnya persatuan dan kesatuan itu sehingga Yesus pun berdoa, "supaya mereka menjadi satu" (Yoh. 17:21).22 Kesatuan jemaat dibangun atas pondasi Kristus sebagai Kepala dan jemaat sebagai anggota tubuh-Nya. Setiap anggota tubuh Kristus dipanggil untuk bersekutu, saling mengasihi, menguatkan dan menopang. Kesatuan tubuh Kristus dinyatakan dalam kasih dimana setiap orang dimampukan mengasihi sesamanya. ${ }^{23}$ Persekutuan perlu dirawat untuk menghadirkan kehidupan sosial yang harmonis dengan sikap saling menghargai dan menghormati.

Setiap orang percaya memiliki karunia dan talenta yang berbeda. Karunia atau talenta yang dimiliki setiap individu merupakan kesempatan untuk mengembangkan diri. Karunia yang beraneka ragam itu perlu digali dan dikembangkan agar bermanfaat bagi diri dan kepentingan umat lainnya. Hal ini sejalan juga dengan implementasi sila kedua, yakni "Kemanusiaan yang Adil dan Beradab". Dalam tatanan masyarakat, individu sebagai bagian integralnya bertanggung jawab sesuai dengan posisinya. ${ }^{24}$ Sebagai pemimpin maka ia mengembangkan kepemimpinan yang demokratis, adil dan menjunjung tinggi persatuan, sebaliknya sebagai orang yang dipimpin maka ia akan tunduk dan taat kepada pemimpin. Setiap individu harus mampu menghargai perbedaan namun tetap dalam bingkai kesatuan. Panggilan mewujudkan keadilan sosial dalam masyarakat merupakan tugas dan panggilan gereja. ${ }^{25}$ Sejalan juga dengan implementasi sila kedua, dimana praktek pelayanan diakonia dapat membuktikan realitas kehadiran gereja di tengah masyarakat, yang turut aktif membangun komunitas yang adil dan sejahtera. ${ }^{26}$ Yesus sendiri adalah teladan dalam pelayanan sosial. Selama pelayanan-Nya, Yesus memberi perhatian besar terhadap kelompok masyarakat yang paling rentan terhadap penindasan. ${ }^{27}$ Yesus hadir dan memberi belas kasihan terhadap mereka yang menderita karena sakit, miskin, termarjinalisasi dalam komunitasnya. la memberi makan bagi mereka yang haus dan dahaga; la memberi kesembuhan bagi yang sakit; la menerima mereka yang tersingkirkan; la mengujungi cendekiwan yang memerlukan jawaban; la melawat mereka yang remuk hati; la datang kepada mereka yang putus asa; la datang untuk membebaskan dan menyelamatkan. Kepedulian terhadap sesama merupakan tanggung jawab gereja. ${ }^{28}$ Teladan seperti itulah yang mesti dilakukan gereja sebagai bagian integral masyarakat.

Tampaklah bahwa nilai-nilai Pancasila terekam kuat dalam ajaran Alkitab29, yang menjadi pedoman hidup orang percaya dalam hidupnya. Nilai didalamnya tidak bertentangan dengan iman Kristen yang percaya bahwa keselamatan hanya terdapat didalam Kristus Yesus, melainkan menawarkan kesejukan dalam kehidupan sosial. ${ }^{30}$ Karenanya, menginternalisasi nilai-nilai Pan-

\footnotetext{
${ }^{22}$ Revised Leon et al., "THE GOSPEL ACCORDING" (n.d.).

${ }^{23}$ Kiet Tumiwa et al., "THE UNITY OF TRUE PEOPLE IN THE ACCOUNTING OF THE CHURCH TRITUGAS," Scientific Research Journal (2019).

${ }^{24}$ Benny C. Aker, "Charismata: Gifts, Enablements, or Ministries?," Journal of Pentecostal Theology (2002).

${ }^{25}$ Herry Susanto, "Gereja Sebagai Umat Allah Dan Rekan Negara," Jurnal Jaffray (2019).

${ }^{26}$ Norbertus Jegalus, "TANGGUNG JAWAB AWAM DALAM PERUTUSAN DIAKONIA GEREJA," Lumen Veritatis: Jurnal Filsafat dan Teologi (2020).

${ }^{27}$ Muryati Muryati, "Gereja Dan Panggilan Missio Ecclesiae," in Reaffirming Our Identity, ed. Junifrius Gultom and Frans Pantan, 1st ed. (Jakarta: STT Bethel Indonesia, 2014), 239.

${ }^{28}$ Frans Pantan, "Pendidikan Sebagai Tanggungjawab Gereja," in Bergereja Dalam Bingkai Kebangsaan, ed. Junifrius Gultom and Frans Pantan, 1st ed. (Jakarta: STT Bethel Indonesia, 2016), 24.

${ }^{29}$ Setyobekti, Kathryn, and Sumen, "Implementasi Nilai-Nilai Bhineka Tunggal Ika Dalam Membingkai Keberagaman Pejabat Gereja Bethel Indonesia Di DKI Jakarta."

${ }^{30}$ Gernaida K R Pakpahan, Frans Pantan, and Epafras Djohan Handojo, "Menuju Gereja Apostolik Transformatif" 5, no. 1 (2021): 136-146.
} 
casila dalam hidup orang percaya menjadi tindakan nyata dalam menghadirkan berita syalom bagi masyarakat dan bangsa.

\section{Integrasi Nilai Pancasila di lingkungan kampus STT Bethel}

STT Bethel sebagai Kampus keagamaan mempunyai peran signifikan dalam mengintegrasikan nilai-nilai Pancasila dengan segenap sivitas akademiknya. Keberadaan kampus yang berada dalam lingkungan multikultur menjadi cermin bahwa dengan Pancasila sebagai idiologi bersama harus mampu merangkai perbedaan yang telah dikarunikan oleh Tuhan dan berusaha merekatkan persatuan dan kesatuan yang telah terbentuk guna menciptakan kehidupan yang rukun dan saling menghargai. Internalisasi value Pancasila diupayakan oleh STT Bethel dengan membangkitkan dan menyalakan spirit Pancasila bagi pribadi mahasiswa. Internalisasi value ini akan mendorong pemahaman yang lebih dalam (deep), mengerti, dan mampu mengamalkan nilainilai Pancasila dalam realitas interaksi sosial masyarakat. Dengan menanamkan nilai-nilai Pancasila bagi sivitas mahasiswa dan warga sekitar kampus, akan mengembalikan pemahaman secara utuh mengenai Pancasila.

Mahasiswa kampus STT Bethel, dalam mengimplementasikan nilai-nilai Pancasila, bisa dengan interaksi antarsesama yang bersifat saling menghargai, menghormati dan berperilaku santun. Selain itu, integrasi nilai Pancasila juga dilaksanakan dalam proses pembelajaran di lingkungan kampus, dimana dalam setiap perkuliahan selalu diawali dengan doa yang menandakan tingkat religiusitasnya individu mahasiswa.

Berdasarkan analisis angket terhadap butir 1; apakah pelajar Pancasila mempunyai kepentingan dalam merespon pandemi Covid-19, didapati hasil 43,2\% menjawab selalu, 27,3\% menjawab sering, dan 27,3 \% menjawab kadang-kadang. Implikasi dari butir pertama setidaknya menjadi bukti bahwa pelajar Pancasila dalam konteks di lingkungan STT Bethel memiliki respon yang tinggi. Dalam konteks aktualisasinya, secara tidak langsung berada pada katagori tinggi. Melalui nilai Pancasila yang ajarkan, maka peserta dapat mengenai ideologi bangsanya sendiri. Lebih lanjut, setiap peserta didik diarahkan untuk memiliki ketajaman dalam melihat realita di masyarakat yang majemuk sebagai suatu kekayaan yang harus dijaga dan dilestarikan. Karena itu, pelajaran apapun mesti diarahkan kepada semangat dalam Pancasila.

Nilai-nilai luhur Pancasila di lingkungan kampus STT Bethel telah menjadi kesepakatan bersama untuk saling menjaga, dan mengamalkan sila-sila yang terdapat dalam Pancasila. Implementasi sila pertama, kedua, dan keempat dikuatkan berdasarkan analisis angket yang berhubungan kemandirian, gotong royong terimplementasikan dalam kehidupan sehari-hari. Hasil analisis diperoleh $42,4 \%$ yang menjawab selalu, 39,4\% menjawab sering, dan 15,2\% menjawab kadang-kadang. Hal ini mengindikasikan bahwa implementasi nilai Pancasila teraktualisasikan dalam katagori tinggi di lingkungan kampus STT Bethel. Respon terhadap item tersebut setidaknya yang mengisis angket mewakili dari perspektif hetereogenitas yang ada didalam lingkungan Bethel, seperti asal ususl mahasiswa dari berbagai suku di Indonesia, sikap gotong royong, dan rasa persaudaraan dan kekeluargaan yang erat sejak menjadi mahasiswa pada semester pertama sampai akhir.

Konteks kebijakan yang dikeluarkan oleh pihak kampus STT Bethel, penerimaan akan realitas berbeda yang melahirkan sikap bersatu dan saling menghargai terdapat di sekitar kampus, semua sivitas akademik agar memiliki keseriusan untuk internalisasi nilai-nilai Pancasila dalam kehidupan sehari-hari sebagai makhluk sosial. Adanya pengedepanan diferensiasi dan pertentangan dalam keseharian kampus STT Bethel justru dihindari dalam iklim perkuliahan, karena stakeholder memiliki kebijakan kebersamaan merupakan kunci mengatasi perbedaan yang ada di dalam masyarakat secara umum, khususnya di lingkungan kampus STT Bethel.

\section{Pancasila dan tantangannya di Lembaga Pendidikan Keagamaan}

Tantangan yang dihadapi lembaga pendidikan keagamaan adalah, pertama, munculnya kelompok sektarian. Sektarianisme akan bertumbuh subur bila diberi kesempatan terhadap kelompok yang melihat kelompok lain di luar dirinya berbeda baik dalam politik, agama, budaya sehingga 
kelompok yang berbeda itu dapat diperlakukan secara diskriminatif, dibenci oleh karena adanya perbedaan pandangan baik di dalam dan antar agama, latar belakang politik maupun budaya. Sektarianisme cenderung ekslusif dan tertutup terhadap pihak lain, sehingga pemaksaan terhadap keseragaman dengan dirinya, dan hal ini semakin memperkuat politik identitas. ${ }^{31}$ Pada situasi demikian integrasi nilai-nilai Pancasila dalam masyarakat menjadi tertutup.

Kedua, penyalahgunaan konsep multikulturalisme sebagaimana terkandung dalam nilai Bhineka Tunggal Ika, dengan tujuan kepentingan-kepentingan kelompok tertentu. ${ }^{32}$ Sejarah Indonesia membuktikan selama periode Orde Baru, multikuluralisme dikendalikan penguasa untuk melanggengkan kedudukan dan kepentingannya. Faktanya, masyarakat terdapat banyak pembatasan sosial, agama dan politik yang justru menjadi alat yang dengan mudah tersulut hingga membuat permusuhan. ${ }^{33}$ Namun ketika masa reformasi, kebebasan seolah tidak ada kekang sehingga dengan bebas menyampaikan pendapat termasuk narasi yang mendiskreditkan kelompok lain dianggap legal. Multikulturalisme merupakan sebuah fakta bahwa Indonesia kaya akan keragaman yang dipersatukan sebagai kekuatan bangsa. ${ }^{34}$

Ketiga, penyalahgunaan teknologi dan informasi. Manusia adalah mahluk yang cerdas dan kreatif, yang senantiasa mengembangkan pengetahuan dan teknologi demi kemajuan peradaban manusia. 35 Tujuannya mulia, yakni meningkatkan kehidupan manusia baik sebagai individu maupun masyarakat luas. Dengan teknologi informasi maka dunia semakin mudah dijangkau. Waktu yang digunakan untuk menyelesaikan tugas semakin cepat dan efisien. Metadata dapat diakses dengan muda sehingga menolong manusia memperoleh informasi, pengetahuan dan peningkatan kinerja dan karyanya. Namun penyalahgunaan teknologi digunakan sekelompok orang untuk mengindoktrinasi dan menanamkan bibit radikalisme. ${ }^{36}$ Teknologi inforasi, khususnya media sosial dapat digunakan menyebarkan berita negatif, bulliying, hoax, intimidasi, dan propaganda untuk kepentingan kelompoknya. ${ }^{37}$ Di sinilah tantangan lembaga pendidikan, mengingat pengguna media sosial kebanyakan dari pelajar atau mahasiswa.

Keempat, membangun dialog yang terus menerus. Menjaga kekutuhan NKRI berarti mempertahakan nilai-nilai Pancasila secara konsekuen dan berkelanjutan. ${ }^{38}$ Indonesia sejak awal adalah perkumpulan yang kaya dengan berbagai suku, ras, agama, bahasa, budaya yang perlu dirangkul, dirawat dan dilestarikan. ${ }^{39}$ Berbagai tantangan dan permasalahan itu harus hadapi membangun dialog yang terbuka, dimana ada keterbukan di antara sesama anak bangsa. Dialog yang saling menghargai, yang mampu menempatkan kelompok yang berbeda sebagai saudara. Dialog yang saling percaya, dimana tidak ada rekayasa untuk kepentingan kelompoknya.

Uraian diatas setidaknya jika dihubungkan dengan analisis implementasi terhadap nilai-nilai Pancasila, maka pihak STT Bethel memberikan keleluasaan yang maksimal terhadap mahasiswa dalam menerapkan nilai-nilai Pancasila, hal ini berdasarkan telaahan angket diperoleh angka $75,8 \%$ yang menunjukkan bahwa aktualisasinya berada pada katagori tinggi. Lebih lanjut jika melihat keberpihakan pihak STT Bethel terhadap kebijakan yang dikeluarkan oleh pemerintah

\footnotetext{
${ }^{31}$ Syurya Muhammad Nur, "Demokrasi Dan Tantangannya Dalam Bingkai Pluralisme Di Indonesia," Jurnal Ilmiah Mimbar Demokrasi (2019).

${ }^{32}$ Zaenal Abidin, "Menanamkan Konsep Multikulturalisme Di Indonesia," Jurnal Dinamika Global (2016).

${ }^{33}$ Gina Lestari, "Bhinnekha Tunggal Ika: Khasanah Multikultural Indonesia Di Tengah Kehidupan Sara," Jurnal Pendidikan Pancasila dan Kewarganegaraan (2015).

${ }^{34}$ Sudharto, "Multikulturalisme Dalam Pespektif Empat Pilar Kebangsaan," Jurnal Ilmiah CIVIS (2012).

${ }^{35}$ Priskila Issak Benyamin, Ucok P Sinaga, and Febie Yolla Gracia, "Penggunaan 'Platform' Digital Pada

Pembelajaran Pendidikan Agama Kristen Di Era Disrupsi," REGULA FIDEI: Jurnal Pendidikan Agama Kristen 6, no. 1 (2021): 60-68.

${ }^{36}$ Priyantoro Widodo and Karnawati Karnawati, "Moderasi Agama Dan Pemahaman Radikalisme Di Indonesia," PASCA: Jurnal Teologi dan Pendidikan Agama Kristen 15, no. 2 (2019): 9-14.

${ }^{37}$ Machsun Rifauddin and Arfin Nurma Halida, "Waspada Cybercrime Dan Informasi Hoax Pada Media Sosial Facebook," Khizanah al-Hikmah : Jurnal Ilmu Perpustakaan, Informasi, dan Kearsipan (2018).

${ }^{38}$ Rizal Habi Nugroho, "Peranan Pancasila Dan Bhineka Tunggal Ika Dalam Menanggulangi Politik Identitas," Prosiding Senaspolhi (2018).

${ }^{39}$ Miskan, "Pemikiran Multikulturalisme K.H. Abdurrahman Wahid (Gus Dur) Dan Implikasinya Terhadap Pendidikan Agama Islam Di Indonesia," Jurnal Studi Pendidikan Islam (2018).
} 
dalam hal pembelajaran yang mendukung terlaksananya protocol kesehatan diterapkan di lingkungan kampus, berada pada katagori tinggi (90,1\%). Penerapan ini dikarenakan semangat pendidikan Pentakostal terdapat dalam internalisasi Pancasila. Tidak terdapat pertentangan antara keduanya, melainkan sejalan dalam membentuk pemimpin yang memiliki keterbukaan berpikir dan keterampilan dalam kehidupan sosial masyarakat. ${ }^{40}$ Hasil temuan ini dapat menjadi acuan untuk meningkatkan internalisasi nilai-nilai Pancasila agar dapat menekan sikap radikalisme yang bertumbuh dengan cepat di kalangan Mahasiswa. Selain itu, menerapkan prinsip digitalisasi dan menggunakan platform-platform digital dalam menginternalisasikan nilai-nilai Pancasila dengan tujuan menarik perhatian Mahasiswa yang generasi Milenial.

\section{KESIMPULAN}

Pancasila sebagai dasar negara Indonesia memberikan pengaruh yang besar dalam segala aspek kehidupan. Keputusan yang sudah final akan dasar negara Indonesia adalah Pancasila adalah keputusan yang tepat, bukan karena menguntungkan bagi satu golongan, khususnya Kekristenan, melainkan, kepada seluruh golongan yang ada, baik secara agama, sosial, pendidikan, dan kelompok masyarakat lainnya. Hal ini yang diserap oleh STT Bethel Indonesia untuk membumikan nilai luhur Pancasila kepada setiap mahasiswa dan para dosen yang ada. Secara kelembagaan, STT Bethel mengeluarkan kebijakan agar seluruh bagian dan stakeholder menjunjung nilai kebersamaan dan saling mengormati. Semangat ini adalah implementasi dari nilai Pancasila yang diajarkan dalam kelas-kelas pembelajaran. Itu sebabnya, setelah mahasiwa menempuh Pendidikan dan diutus ke daerah asalnya, nilai kebersamaan dan kesatuan itu diimplementasikan kepada masyarakat gereja. Hal ini berjalan lurus dengan nilai mengasihi Tuhan dan mengasihi sesama yang menjadi mandat utama yang Tuhan berikan (Kej. 1:28). Oleh karenanya, pendidikan yang berbasis nilai Pancasila seharusnya terus diintegrasikan dalam kebijakan kampus dan kurikulum pembelajaran. Bukan hanya dalam satu mata kuliah Kewarganegaraan, melainkan seluruh mata pelajaran/kuliah yang ada, karena integrasi ini tidaklah bertentangan dengan nilai iman Kristen.

\section{REFERENSI}

Abidin, Zaenal. "Menanamkan Konsep Multikulturalisme Di Indonesia." Jurnal Dinamika Global (2016).

Aker, Benny C. "Charismata: Gifts, Enablements, or Ministries?" Journal of Pentecostal Theology (2002).

Amos Hosea. "Karakteristik Pendidikan Iman Dalam Pentakostalisme." Diegesis : Jurnal Teologi 4, no. 2 (2019): 51-57.

Basri, Basri, and Nawang Retno Dwiningrum. "Potensi Radikalisme Di Perguruan Tinggi ( Studi Kasus Di Politeknik Negeri Balikpapan )." Jurnal Sosial Humaniora dan Pendidikan 3, no. 1 (2019): 84-91.

Benyamin, Priskila Issak, Ucok P Sinaga, and Febie Yolla Gracia. "Penggunaan 'Platform' Digital Pada Pembelajaran Pendidikan Agama Kristen Di Era Disrupsi." REGULA FIDEI: Jurnal Pendidikan Agama Kristen 6, no. 1 (2021): 60-68.

Doddy, Doddy. "Internalisasi Nilai-Nilai Pancasila Perlu Diperkuat." Direktorat Jenderal Pendidikan Tinggi Kementerian Pendidikan, Kebudayaan, Riset Dan Teknologi.

Hantoro, Juli. "Pasien Covid-19 Cluster Bethel Petamburan Dirujuk Ke Wisma Atlet." Metro Tempo. Jakarta, 2020. https://metro.tempo.co/read/1332388/pasien-covid-19-clusterbethel-petamburan-dirujuk-ke-wisma-atlet/full\&view=ok.

Hidayat, Fadhil Pahlevi, and Faizal Hamzah Lubis. "Literasi Media Dalam Menangkal Radikalisme Pada Siswa" 5, no. 1 (2021): 31-41.

${ }^{40}$ Amos Hosea, "Karakteristik Pendidikan Iman Dalam Pentakostalisme," Diegesis : Jurnal Teologi 4, no. 2 (2019): 51-57. 
Jegalus, Norbertus. "Tanggung Jawab Awam Dalam Perutusan Diakonia Gereja." Lumen Veritatis: Jurnal Filsafat dan Teologi (2020).

Kaelan, and Achmad Zubaidi. Pendidikan Kewarganegaraan Untuk Perguruan Tinggi. Yogyakarta: Paradigma, 2007.

Kebudayaan, Kementerian Pendidikan dan. "Visi Misi Kementerian Pendidikan Dan Kebudayaan." Kementerian Pendidikan Dan Kebudayaan. Last modified 2020. https://www.kemdikbud.go.id/main/tentang-kemdikbud/visi-dan-misi.

Lattu, Izak. "Performative Interreligious Engagement: Thinking About Sociology of Interreligious Relations [Performative Interreligious Engagement: Memikirkan Sosiologi Hubungan Lintas Agama]." In Sosiologi Agama Pilihan Berteologi Di Indonesia, 25 Tahun Pasca Sarjana Sosiologi Agama Universitas Kristen Satya Wacana. Salatiga: Fakultas Teologi UKSW, 2016.

Leon, Revised, Morris Hailed, Christianity Today, Leon Morris, Fourth Gospel, New Testament, The Gospel, et al. "THE GOSPEL ACCORDING" (n.d.).

Lestari, Gina. "Bhinnekha Tunggal Ika: Khasanah Multikultural Indonesia Di Tengah Kehidupan Sara." Jurnal Pendidikan Pancasila dan Kewarganegaraan (2015).

Miskan. "Pemikiran Multikulturalisme K.H. Abdurrahman Wahid (Gus Dur) Dan Implikasinya Terhadap Pendidikan Agama Islam Di Indonesia." Jurnal Studi Pendidikan Islam (2018).

Muryati, Muryati. "Gereja Dan Panggilan Missio Ecclesiae." In Reaffirming Our Identity, edited by Junifrius Gultom and Frans Pantan, 239. 1st ed. Jakarta: STT Bethel Indonesia, 2014.

Nugroho, Rizal Habi. "Peranan Pancasila Dan Bhineka Tunggal Ika Dalam Menanggulangi Politik Identitas." Prosiding Senaspolhi (2018).

Nugroho, Wisnu. "Bom Bunuh Diri Di Gerbang Katedral Makassar Dan Ancaman Teror Serentak." Kompas News. Jakarta, 2021. https://www.kompas.com/tren/read/2021/03/30/090623665/bom-bunuh-diri-di-gerbangkatedral-makassar-dan-ancaman-teror-serentak?page=all.

Nur, Syurya Muhammad. "Demokrasi Dan Tantangannya Dalam Bingkai Pluralisme Di Indonesia." Jurnal Ilmiah Mimbar Demokrasi (2019).

Pakpahan, Gernaida K R, Frans Pantan, and Epafras Djohan Handojo. "Menuju Gereja Apostolik Transformatif" 5, no. 1 (2021): 136-146.

Pantan, Frans. "Pendidikan Sebagai Tanggungjawab Gereja." In Bergereja Dalam Bingkai Kebangsaan, edited by Junifrius Gultom and Frans Pantan, 24. 1st ed. Jakarta: STT Bethel Indonesia, 2016.

Rifauddin, Machsun, and Arfin Nurma Halida. "Waspada Cybercrime Dan Informasi Hoax Pada Media Sosial Facebook." Khizanah al-Hikmah : Jurnal Ilmu Perpustakaan, Informasi, dan Kearsipan (2018).

Salman, Ibnu, Priskila Benyamin, and Wartoni Wartoni. "Monitoring Model and Evaluation of ICT Utilization in The New Normal Era in Distance Learning in Madrasah" (2021): 1-8.

Schwartz, H, and J Jacobs. Qualitative Sociology: A Method to The Madness. New York: Free Press, 1979.

Septian, Doni. "Pemahaman Nilai-Nilai Pancasila Dalam Memperkuat Kerukunan Umat." TANJAK: Journal of Education and Teaching (2020).

Setyobekti, Andreas Budi. "Mengafirmasi Kembali Nilai-Nilai Pengajaran Gereja Bethel Indonesia." In Reaffirming Our Identity: Isu-Isu Terpilih Menjawab Perubahan Sekaligus Mempertahankan Identitas, edited by Junifrius Gultom and Frans Pantan. Jakarta: Bethel Press, 2014.

Setyobekti, Andreas Budi, Susanna Kathryn, and Suwondho Sumen. "Implementasi Nilai-Nilai Bhineka Tunggal Ika Dalam Membingkai Keberagaman Pejabat Gereja Bethel Indonesia Di DKI Jakarta." SOTIRIA (Jurnal Theologia dan Pendidikan Agama Kristen) 4, no. 1 (2021): 1-10.

Steinmann, Andrew. Genesis: An Introduction and Commentary. Tyndale Old Testament Commentaries, 2019. 
Subagyo, Agus. "Implementasi Pancasila Dalam Menangkal Intoleransi, Radikalisme Dan Terorisme." Jurnal Rontal Keilmuan Pancasila dan Kewarganegaraan 6 (1) (2020).

Sudharto. "Multikulturalisme Dalam Pespektif Empat Pilar Kebangsaan." Jurnal IImiah CIVIS (2012).

Suhendra, Ryan Hadi. "Massa Berkumpul Dekat Markas FPI , Aparat TNI Dan." CNN Indonesia. Jakarta, November 2019.

https://www.cnnindonesia.com/nasional/20191001021328-20-435512/massa-berkumpuldekat-markas-fpi-aparat-tni-dan-polri-siaga.

Susanto, Herry. "Gereja Sebagai Umat Allah Dan Rekan Negara." Jurnal Jaffray (2019).

Tjarsono, Idjang. "Demokrasi Pancasila Dan Bhineka Tunggal Ika Solusi Integrasi." Transnasional (2013).

Tumiwa, Kiet, Jolly Turangan, Lusye C. Kumaat, and Johana Ratag. "The Unity Of True People In The Accounting Of The Church Tritugas." Scientific Research Journal (2019).

Untung, Naftali. "Kristus Dan Perempuan Samaria: Yohanes 4:1-42." In Misi Inklusif: Berjumpa Dengan Firman Dan Realitas Untuk Misi Yang Inklusif, 96. Jakarta: STT Bethel Indonesia, 2017.

Widjaja, Paulus Sugeng. "Aktualisasi Pancasila Berdasarkan Etika Kebajikan Kristiani." DUNAMIS: Jurnal Teologi dan Pendidikan Kristiani (2020).

Widodo, Priyantoro, and Karnawati Karnawati. "Moderasi Agama Dan Pemahaman Radikalisme Di Indonesia." PASCA: Jurnal Teologi dan Pendidikan Agama Kristen 15, no. 2 (2019): 9-14.

Wiryohadi, Wiryohadi. "Gereja Berbasis Visi Dan Misi Kerajaan Allah." In Reaffirming Our Identity, edited by Junifrius Gultom and Frans Pantan, 261. 1st ed. Jakarta: STT Bethel Indonesia, 2014.

Yun, Joel Suh Tae. "Reading the Fourfold Gospel From the Two Creation Stories in Genesis: A Creation Theological Understanding of the Fourfold Gospel for Holistic Mission." Transformation (2020). 